\title{
Kernos
}

Revue internationale et pluridisciplinaire de religion grecque antique

$25 \mid 2012$

Varia

Giulia SFAMENI GASPARRO, Dio unico, pluralità e monarchia divina. Esperienze religiose e teologie nel mondo tardo-antico

\section{Francesco Massa}

\section{OpenEdition}

\section{Journals}

Édition électronique

URL : http://journals.openedition.org/kernos/2094

DOI : 10.4000/kernos.2094

ISSN : 2034-7871

\section{Éditeur}

Centre international d'étude de la religion grecque antique

\section{Édition imprimée}

Date de publication : 26 octobre 2012

Pagination : 383-385

ISSN : 0776-3824

\section{Référence électronique}

Francesco Massa, « Giulia SFAmENI GASPARRo, Dio unico, pluralità e monarchia divina. Esperienze religiose e teologie nel mondo tardo-antico », Kernos [En ligne], 25 | 2012, mis en ligne le 01 octobre 2012, consulté le 21 septembre 2020. URL : http://journals.openedition.org/kernos/2094 ; DOI : https://doi.org/10.4000/kernos.2094

Ce document a été généré automatiquement le 21 septembre 2020 


\title{
Giulia SFAMENI GASPARRO, Dio unico, pluralità e monarchia divina. Esperienze religiose e teologie nel mondo tardo-antico
}

\author{
Francesco Massa
}

\section{RÉFÉRENCE}

Giulia SFAMENI GASPARRO, Dio unico, pluralità e monarchia divina. Esperienze religiose e teologie nel mondo tardo-antico, Brescia, Morcelliana, 2010. 1 vol. 15,5 × 22,5 cm, 280 p. (Scienze e storia delle religioni). ISBN : 978-88-372-2433-2.

1 Ces dernières années, le débat scientifique autour de la question du prétendu «monothéisme païen » a connu un grand succès et a produit un nombre considérable d'articles et d'ouvrages. Le point de départ du débat savant est représenté par un ouvrage issu d'un séminaire oxonien édité par Polymnia Athanassiadi et Michael Frede $^{1}$. Ce livre présente les réflexions de plusieurs spécialistes des religions et des philosophies de l'Antiquité qui ont choisi d'attribuer l'étiquette de «monothéisme » à toute forme religieuse articulée autour de la contemplation de l'idée d'un principe premier. Récemment, d'autres publications ont abordé la question en adoptant des perspectives différentes, comme les deux volumes, issus d'un projet de recherche de l'Université d'Exeter et édités par Stephen Mitchell et Peter van Nuffelen ${ }^{2}$ : ces deux livres couvrent un arc chronologique très large, $\mathrm{du}^{\mathrm{er}}$ au v $\mathrm{v}^{\mathrm{e}}$ siècle, en s'intéressant à la fois aux pratiques rituelles et aux discours philosophiques et théologiques, afin de comprendre les formes et la nature des «monothéismes » des premiers siècles de notre ère.

2 Le livre de Giulia Sfameni Gasparro (G.S.F.) se situe dans cet important courant d'études, même si l'A. étend la perspective en présentant six essais relatifs à des 
auteurs de l'époque impériale romaine appartenant aux milieux polythéiste, juif et chrétien: ces analyses portent sur des sujets précis qui questionnent, selon des perspectives différentes, non seulement la pertinence de la notion de «monothéisme païen ", mais aussi les différentes représentations de l'unité et de la pluralité divine à l'époque impériale romaine. En guise de préalable à ces six études, l'Introduction livre des outils herméneutiques et théoriques. G.S.F. se penche tout d'abord sur des questions de terminologie, en analysant l'histoire des catégories du " monothéisme » et du " polythéisme » : elle affirme sa préférence pour le terme de " polythéisme » plutôt que celui de "paganisme ", puisque la première notion lui apparaît moins tributaire de la conception chrétienne des phénomènes religieux des mondes grec et romain. Le "polythéisme », bien qu'il soit attesté occasionnellement dans les sources anciennes (notamment chez Philon d'Alexandrie), pourrait être défini comme un ensemble de divinités, unies généralement par des rapports familiaux et liées au fonctionnement de la vie cosmique et humaine. Ensuite, l'A. revient sur la signification moderne du terme " monothéisme ", telle qu'elle a été conçue en Angleterre au XVII siècle, dans le cadre des spéculations philosophiques et théologiques de H. More, penseur du cercle des platoniciens de Cambridge.

3 L'une des thématiques de l'ouvrage concerne la conception, répandue dans les différentes formes religieuses du monde méditerranéen ancien, selon laquelle on pouvait arriver à la contemplation de dieu et du divin par la contemplation du monde. Les ouvrages de Philon s'inscrivent dans ce contexte historique et religieux, en intégrant les formes du mysticisme astral de l'époque sans nier leur danger : toutefois la théologie philonienne est centrée sur la vraie connaissance du Dieu de la révélation biblique et l'analyse de G.S.F. met ainsi en relief la spécificité de la pensée de Philon, qui fait d'Abraham le fondateur du monothéisme face à l'erreur des polythéismes. Toujours dans le cadre du judaïsme hellénistique, l'A.travaille sur l'image d'un Orphée monothéiste chez plusieurs auteurs chrétiens des premiers siècles de notre ère. Elle met en lumière la pratique "d'apprivoisement» du patrimoine idéologique de nombreuses écoles philosophiques grecques: on peut observer chez les auteurs chrétiens un processus de sélection des éléments des théologies philosophiques grecques qui pouvaient entrer dans le nouveau système théologique chrétien. Nous pourrions remarquer qu'il s'agit là du même mécanisme de récupération et de resémantisation partielle mis en œuvre par les auteurs chrétiens sur le vocabulaire et les images des mondes grec et romain.

4 Un deuxième axe de la recherche est représenté par les catégories de "monarchie divine ", de "Dieu unique » et de "monothéisme païen ». L'A. s'attache à définir la notion de monothéisme et, dans ce but, analyse plusieurs passages du philosophe néoplatonicien Proclus qui, dans le Commentaire au Parménide, montre son aversion à l'égard de la nouveauté chrétienne et refuse, en particulier, le pouvoir créateur que les chrétiens attribuent à leur Dieu, en déclarant la transcendance absolue du Premier Dieu. G.S.F. souligne que, même si les élites intellectuelles des mondes anciens ont toujours essayé de concilier leurs systèmes idéologiques avec les croyances et les pratiques réellement attestées, la diffusion du message religieux chrétien les a obligés à donner une justification rationnelle à leurs structures religieuses. En outre, en se fondant sur un panorama de la polémique entre " païens » et « chrétiens » à propos de la représentation du divin, l'A. propose une définition plus large de la notion de "monothéisme» qui ne peut pas se réduire à son opposition au "polythéisme». Il s'agit là d'une des propositions les plus importantes pour comprendre, d'un point de 
vue théorique et épistémologique, les réalités religieuses de l'époque : G.S.F. affirme que la distinction entre les formes religieuses différentes repose sur «la qualité historico-religieuse d'un Dieu personnel et créateur, vivement actif dans l'histoire humaine» (p. 129).

Le cœur de la réflexion proposée par G.S.F. est représenté par la question du « monothéisme païen » : elle identifie chez les auteurs platoniciens des premiers siècles de notre ère une théologie qui se propose de concilier la transcendance d'un Dieu très haut et innommable et la présence d'une multitude de figures divines présentes dans les panthéons traditionnels. Il s'agit donc d'une sorte de "koinè idéologique " homogène. Le grand intérêt de cette partie de l'ouvrage est de présenter les positions d'auteurs moins connus, comme Onatas, Maxime de Tyr, et Macaire de Magnésie. La nécessité de distinguer l'aspect théorique de ses reflets dans la pratique religieuse conduit l'A. à mettre en lumière l'inclusion des divinités traditionnelles dans le système théologique mis en place par les auteurs platoniciens. L'analyse permet de déterminer l'existence d'une sorte de «monarchie divine » qui n'empêche pas la conservation des pratiques religieuses traditionnelles. G.S.F. montre donc que l'emploi de la catégorie de "monothéisme païen", en procédant de la tendance à identifier sous la même étiquette des phénomènes qui restent au fond différents, perd par là-même sa valeur heuristique.

6 Le livre de G.S.F. propose au lecteur un parcours très riche où les différents thèmes spécifiques abordés s'intègrent à une structure unitaire. L'analyse et la comparaison des textes païens, juifs et chrétiens au moyen des catégories de "monothéisme » et de "pluralité divine » permettent de réfléchir sur les mécanismes de la construction des identités religieuses pendant les siècles de cohabitation des groupes religieux de l'Antiquité tardive : les identités se construisent précisément sur la base des conflits et des compétitions entre groupes religieux, en mobilisant le passé et l'histoire dans le but de justifier la situation présente. L'analyse des théologies de la Méditerranée des premiers siècles de notre ère et des multiples facettes de la conceptualisation et de la représentation de l'unicité divine dans les milieux païens, juifs et chrétiens se révèle particulièrement utile aux historiens des religions de l'Empire romain. Elle permet de comprendre comment se sont établies les relations religieuses et culturelles dans une période de basculement religieux. Enfin, le présent ouvrage constitue un outil de recherche de grand intérêt tant pour la richesse de ses notes et de ses références bibliographiques que pour les parcours historiographiques qu'il restitue afin d'éclairer les débats scientifiques actuels.

\section{NOTES}

1. P. AthanAssiadi, M. Frede (éds), Pagan Monotheism in Late Antiquity, Oxford, Clarendon Press, 1999.

2. St. mitchell, P. VAN NUffelen (éds), Monotheism between Christians and Pagans in Late Antiquity, Leuven, Peeters, 2009 et One God. Pagan Monotheism in the Roman Empire, Cambridge, University Press, 2010. 


\section{AUTEURS}

\section{FRANCESCO MASSA}

Laboratoire d'excellence HASTEC - Paris 